\title{
Health Information Literacy: An Assessment of Commercial Bus Drivers' Patronage of 'Mama Put' Food Outlet, and Their Sense of Vulnerability to Food Poison
}

\author{
Allen Nnanwuba Adum \\ Department of Mass Communication, \\ Nnamdi Azikiwe University, Awka, \\ Anambra State, Nigeria \\ Nze Uchenna Nze \\ Department of Mass Communication, \\ Tansian University, Umunya, \\ Anambra State, Nigeria \\ Emeka Odogwu \\ Department of Mass Communication, \\ Nnamdi Azikiwe University, Awka, \\ Anambra State, Nigeria \\ Kobimdi Umeh \\ Department of Mass Communication, \\ Nnamdi Azikiwe University, Awka, \\ Anambra State, Nigeria
}

\begin{abstract}
Health information can be an effective means of guiding consumers to healthy eating as well as make them aware of certain diseases that can be contacted as a result of unhygienic environment where food is prepared or sold. Despite hygienic environment, little is known about the actual impact of health information literacy on commercial bus drivers about "mama put" food outlets. The work was an empirical study and survey research design was adopted. The work was anchored on Consumer Pull Model. Data were collected in Onitsha, Anambra State, Nigeria among commercial bus drivers by administering questionnaire to a sample of 352 respondents at Upper Iweka Motor Park, Onitsha. This study found that commercial bus drivers in Onitsha are not health information literate and not aware that patronizing "mama put" food outlets make them vulnerable to food poison. It also established that price of a plate of food and quantities are two major factors that influence commercial bus drivers to patronize mama put food outlets. Based on these findings, this study recommended that health regulatory bodies should educate both the "mama put" food vendors and the commercial bus drivers on the importance of hygienic environment where food is prepared or sold.

Keywords: Health information literacy, "Mama Put", Commercial bus drivers, hygienic environment, Food poison.

DOI: $10.7176 / \mathrm{JPID} / 50-08$

Publication date: June $30^{\text {th }} 2019$

\section{INTRODUCTION}

Nigerian cities are flooded with hundreds of food vendors. At every corner of each city you see food vendors popularly known as "mama put". These food vendors save many people from all walks of life including commercial bus drivers, the time and money, going to standard/fancy restaurant inside the cities; World Health Organisation (WHO) (2004) states that the information about food content and the hygienic environment where food is cooked or served is particularly important. Whether the commercial bus drivers are away that the patronage to the mama put food vendors increases their vulnerability to food poison is the focus of this study.

According to Odeyemi (2015), long before the influx and spread of contemporary restaurants and eateries in Nigeria, Mama Put has been a reliable and affordable substitute to home cooking for many Nigerians. With no clear trace to the origin or history of the name Mama Put, Nigerians still remain attached to this popular tag used in generalising small food sheds, local canteens and mini restaurants in open spaces, make shift restaurants, wooden kiosks or brick-walled shops where food vendors serve all kinds of staple and indigenous foods at pretty
\end{abstract}


affordable prices. In the past, these local canteens were the major components making up Nigeria's food-selling sector, until modern day restaurants and eateries began to sprout in cities and different franchises surfaced in rural areas. Some food vendors resort to hawking due to high cost of renting a shop. Although the emergence of these chain of fancy food outlets brought a new side to the overall offerings of the nation's hospitality subsector, the ever-growing gap in the social statuses of Nigerians has given 'Mama Put' a clear edge in the industry till date.

Adunwoke (2015) states that the growing patronage many of these food sellers enjoy in big cities may be due to the peculiarity of such environment where offering food for sale by roadside or through hawking thrive. In these cities and communities, many who visit these joints do so because the pricing is friendly to the lower cadre of the members of the society. Also, many who patronise these food vendors are commercial bus drivers and other people on the move and who operate within the locality of these roadside food sellers.

Khairuzzaman, Chowdhury, Emon and Bari (2014) posit that food vending is a significant part of the urban food supply. Street-vending of foods is also an important mean of employment as a significant number of women are employed in this sector. Odeyemi (2015) stresses that offering considerably cheap meals that fit well into the budget of the high, middle and low class, Mama Put has won the loyalty of many who can only afford to visit pricy restaurants on special occasions and several others, who in spite of their comfort or affluence simply like the idea of patronising small scale canteens just for the satisfaction they derive from the taste of locally prepared meals.

Mama put exists in every motor park in Nigeria. The size of the park determines the number of mama put food outlets to be seen in the park. Many drivers always hope on them on daily basis because they are always on the move. Adunwoke (2015) states that after letting off his passengers at the park, the first thing a commercial bus driver does is to eat at any of the mama put outlets at the park. They equally do same before taking off depending on the distance of the journey. As a result, Mama Put has for many years retained the responsibility of serving commercial bus drivers who always have tight work schedules. Also, the 'eating out' trend, which remains a common habit to many commercial bus drivers in Nigeria and other parts of the world, is constantly contributing to the longstanding boom in small-scale food businesses and the entire food industry at large.

Today, many Mama Put owners especially those with tasty meals and large customer base in motor parks in big cities like Abuja, Kano, Lagos, Onitsha, Port Harcourt etc have been able to expand their businesses within a short period of time. Some who started out with just a few food warmers with a big umbrella in motor parks have constructed or hired kiosks at same motor parks. Beside the stress of large scale cooking, the cheap start-up cost and unbelievable daily dividends make it a very rewarding business for those who understand how to keep it moving. In motor parks, many mama put food vendors operate round-the-clock. Odeyemi (2015) posits that a greater percentage of food what mama put outlets serve to commercial bus drivers are mainly staples like rice, beans, yam pottage, plantain, etc, while others serve commonly requested indigenous dishes like 'amala and ewedu,' 'eba and edikaikong,' 'pounded yam and vegetable soup,' and a host of many others. Apart from the staple foods, each mama put food vendor operating in any motor park in Nigeria equally have to serve cultural foods of the tribe where the park is located. If the park is located in Lagos, amala and ewedu must be in the menu; Onitsha- akpu/eba and egwusi/onugbu soup; Calabar- eba and edikaikon and so on.

Although the constant patronage of these food vendors at motor parks is not to say that the business is devoid of its own shortcomings, like unhealthy cooking environments for some and substandard food items and ingredients for others, many commercial bus drivers don't seem to mind as long as the meal suits their taste. This explains the somewhat baffling yet intriguing 'Mama Put' craze featuring customers, who despite the heat and congestion, religiously wait in line drooling over large warmers of steaming hot food or pots boiling over openbelly fire wood stoves. As a matter of fact, one unassailable perk of the 'Mama Put' business remains the fact that it will always be shielded from economic storms. Unlike bigger restaurants and eateries that are vulnerable to harsh economic situations, causing commercial bus drivers to cut back on extravagance, these smaller food canteens still thrive, as commercial bus drivers and their bus conductor can afford most of its meals even in the toughest of situations. (Odeyemi, 2015).

According to a 2007 study from the international Food and Agriculture Organisation (FAO), about 2.5 billion people eat street food every day worldwide. So this phenomenon is not peculiar in Nigeria. Differences in culture, social stratification and history have resulted in different patterns for how street food vendor enterprises are traditionally created and run in different areas of the world. For example, few women are street food vendors in Bangladesh, but women predominate the trade in Nigeria and Thailand. Regardless of the attendant health risks, it has remained popular, especially among commercial bus drivers, not just in Nigeria, but in many other 
developing countries. It requires low initial capital to start the business. They are inexpensive, convenient and relatively nutritious food centers for urban and rural people. It is also a major source of income for a large number of persons, particularly women and a chance for self-employment. There are many reasons commercial bus drivers buy and eat food from mama put food outlets. Such reasons include: poverty, nearness to their operational unit, ignorance of health information and what constitute healthy eating habit.

\section{STATEMENT OF RESEARCH PROBLEM}

Commercial bus drivers, in most cases, patronise mama put food vendors because of the easy access to the outlet. The food sold by these mama put outlets appears to be cheaper than the ones sold at fancy restaurants. However, the worry is: are commercial bus drivers health information literate? Do commercial bus drivers patronise mama put food outlet? Do commercial bus drivers believe that patronising mama put food outlet easily exposes them to food poison? What factors influence them to patronise mama put food outlet?

\subsection{RESEARCH QUESTIONS}

In order to give direction to the investigation, the following research questions were posed:

1. To what extent are commercial bus drivers health information literate?

2. To what extent do they patronise mama put food outlet?

3. To what extent do they believe that patronising mama put food outlet easily exposes them to food poison?

4. What factors influence them to patronise mama put food outlet?

\section{HEALTH RISK OF MAMA PUT FOOD OUTLETS}

Former President, Association of Resident Doctors, Lagos University Teaching Hospital (LUTH), Dr. Omojowolo Olubunmi in an interview in with Guardian newspaper in 2015 stated that many vendors running mama put food outlet prepare and sell such in unclean environment. Furthermore, that foods prepared in an unclean environment could be contaminated with microorganisms, which are present in the air, water and the hands of those who sell them. Basically, food or waterborne diseases with predominant feco-oral transmission are the main source of concern. Food poisoning caused by Staphylococcus aureus or bacillus cereus, are two of the most common types of bacteria food poisoning. Diseases such as typhoid fever, dysentery, and cholera could be contacted through foods bought by the roadside and parks. Another major public health concern is the use of adulterated, low quality or unsafe ingredients to cook these meals in order to maximise profit. What the consumers are after is quantity and not quality. Olubunmi disclosed that the major challenge of mama put food vendors is that they do not adhere to basic rules of hygiene in the preparation of their foods and if places where the foods are sold are very unhygienic. There are flies, carbon fumes and dusts in the air, which settle on these foods and make them unsafe for human consumption.

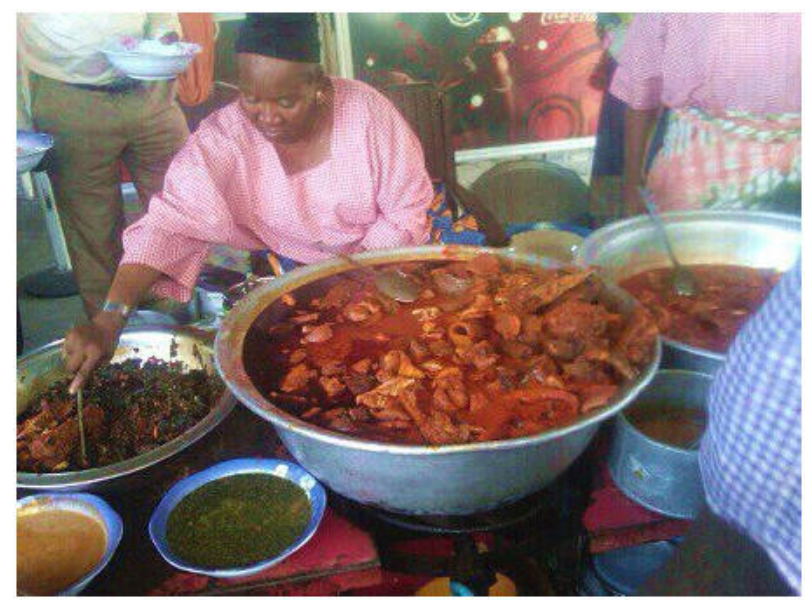

Figure 1: "Mama put” food outlet (Source: Accelerate TV (2017) 
During their public enlightenment in 2015 in Lagos, the National President, Association of Nigerian Nurses and Midwives, Mr. Abdulrafiu Alani Adeniji said that eating in the open market, road side, and other public places may fall short of hygienic condition that is expected to safeguard food contamination or food poison. "There are ways of rendering food unfit for consumption and hazardous, like the food preparation process, storage, dishing and consumption. Adeniji noted that because public places like motor parks; roadside shops are not well planned, there are chances of pollution from refuse, sewage and dumpsites. The health implication of eating in an unhygienic area includes food contamination, food poison, gastroenteritis, cholera, typhoid fevers, acute abdominal pains, worm infestation and other communicable diseases. The burden of this ill-health condition is of grievous implication to man, animal and the entire living. The implication is not limited to health domain. The impact of unhealthy food hygiene extends to decreased productivity, loss of man hour, and absenteeism on duty.

Khairuzzaman (2014) is of the view that the number of food poisoning notifications rose steadily worldwide since the inception of E. coli O157:H7 outbreak in the 1980s to date. This may be partly attributed to improved surveillance, increased global trade and travel, changes in modern food production, the impact of modern lifestyles, changes in food consumption, and the emergence of new pathogens. Mclntyre, Karden, Shyng and Allen (2014) stress that food sold in open place are characterized by a lack of facilities and infrastructure compared to standard restaurant, creating opportunities for preventable hygiene and food contamination issues.

\section{RELEVANCE OF HEALTH INFORMATION}

The importance of health information cannot be relegated to the background in the society. This has made many authorities and agencies in the field of health to always be on their toes to make sure that the consumers derive the proposed benefits that motivate them to purchase cooked food. According to (WHO, 2004), health information stand the chance of encouraging the choice of and consumption of healthful foods, but may also have the inadvertent effect of encouraging excessive intake of specific foods or nutrients. This potential problem is often recognized by existing regulations, which mandate that food must be prepared and sold in a hygienic environment. Concerns have been raised by the ministry of health on the need for the public to know the relationship between the environment where they eat and their health.

WHO (2004) reveals that several existing regulatory agencies have therefore developed mechanisms to inspect environment where foods are not only prepared but also sold to the public. The counter-argument is that health information inherently imply that some foods are prepared and sold in unhygienic environment

Health information can be an effective means of helping consumers to make healthy food choices in hygienic environment, although existing evidence concerning the effect of health information on diet and public health is insufficient (WHO, 2004). Regulations can play a crucial role in enhancing that foods are prepared and sold in a hygienic environment. Countries have many different approaches to select from when constructing a regulatory framework. To maximise the potential of health information literacy to improve public health, regulations will help to develop long-term environmental hygiene across populations as their underlying goal. The effectiveness of health information literacy in improving food consumption patterns relies largely on a motivated and educated public to take into cognizance the hygienic condition of the environment where they eat. This approach has limitations. If there is to be significant change, action on hygienic environment and health information literacy need to be part of an integrated approach that tackles the increasing rates of food-related communicable diseases at a population level, as well as targeting individuals(WHO, 2004). International Food Information Council Foundation (IFICF) (2007) states that health information is a channel to inform the consumers that food prepared in a hygienic environment will help to improve their health.

Hoefkens \& Verbeke (2006) maintain that health information not only draws attention but also motivates the consumer to patronise a product. Real understanding of food information may be sufficient to foster informed food choices, actual healthy choices will largely depend on whether consumers find the stated health effect sufficiently relevant for themselves in the broader context of food choice.

Given that health information is an important motivator of consumers' food choice behavior, Health-Related Motive Orientations (HRMOs) play important role in understanding the health information and taking necessary action. HRMOs are defined as the psychological meanings that people attribute to health and that motivate health behaviour. Two independent motivational systems are distinguished, i.e., an emotion-driven implicit system of non-conscious motives versus a cognition-based explicit system constituted of more conscious goals and values. 
It is expected that people have different health-oriented goals and needs, which may explain differences in health behaviour and, thus, differences in the potential effectiveness between food information that mainly refer to the explicit Health-Related Motive Orientations as a result of the provisions of the regulations of each nation. Despite the fact that the content of health information in particular is restricted by law, food companies still have some degree of freedom, including the specific way in which the health information is communicated so as to draw the attention of the consumers and motivate them to be conscious of what and where they eat.

\section{FACTORS RESPONSIBLE FOR COMMERCIAL BUS DRIVERS' PATRONAGE OF MAMA PUT FOOD OUTLET}

1. It is inexpensive: When you compare the food of mama put or a bukka to the fancy restaurants, there is a huge difference when it comes to cost. Mama put is very affordable and inexpensive. Offering considerably cheap meals that fit well into the budget of the high, middle and low class, 'Mama Put' has won the loyalty of many who can only afford to visit pricey restaurants on special occasions. With $\$ 200$ one can satisfy himself with a full plate of mama put cuisine but that is not same with pricey restaurant. In fancy restaurant, the least price for a plate of food is $\$ 500$ depending on the city and location of the restaurant. That is why you find so many people patronising them.

2. The food is very tasty: To a very large extent, the mama put food is very tasty. Consumers believe mama put foods always have the natural "mama's touch", which most men crave for, after eating all the foreign foods for a while. The food vendors in most cases use local/natural condiments which many believe to offer taste in its nature. The consumers in spite of their comfort or affluence simply like the idea of patronising mama put just for the satisfaction they derive from the taste of locally prepared meals.

3. Variety: Many consumers of mama put food believe that variety is the spice of life. Their view is that the best place you can get food variety is at mama put. From Eba to Eforiro, Edikang ikong, amala and ewedu, Akpu and onugbu soup among others, you will get all of them at mama put. This makes many consumers to patronise mama put so as to choose from varieties.

4. Quantity: Many Nigerians patronise mama put because the food is plentiful. If you are looking for a place to overfeed yourself, then the place to go is the mama put food outlet. The consumers are after quantity and not quality.

5. Easy Access: Mama put food outlets are easy to locate in every city. Those of them that sell at motor parks operate round the clock. This makes it easy for commercial bus drivers and passengers who arrive at the parks at night to see something to eat after a long journey.

\section{THEORETICAL FRAMEWORK}

The study was anchored on Consumer Pull Model. Godin \& Lane (2013) quoting Edgerton (2004) state that Consumer Pull Model originated from the work of William Price and Lawrence Bass in the 1960s. It is a general model that incorporates a number of middle-ranged models of advertising and marketing.

Magloff (2015) writes that Consumer Pull Model is concerned about how the manufacturers use multiple strategies to influence the consumers to patronise their product. Such measures include:

- Promotion

- Price

- Discount to retailers and trade promotions

- Designing and packaging the product in an appealing way

- Maintaining a reputation for reliability and believability

- Writing the utility the consumer stands to gain in the product pack

McNeil (2007) explains that consumer pull model builds on the belief that the value chain starts in the consumer's mind. By understanding the lifestyle needs, income range and social class of the consumer, we must also adopt a price, nutritional and health-oriented perspective (multiple approach) rather than a health benefit (single approach). Manufacturers bear this in mind during the production process.

The theory is of the opinion that consumers go for products that have affordable price which will equally give them the utility they need. Manufacturers understand this. That is the reason they include those ingredients the 
consumers want and still place the product at affordable price. The model believes that consumers purchase a product according to its price and benefits they need. According to McNeil (2007) the theory contends that manufacturers record high volume of sales or their products having a high market share because they not only include those benefits that will attract the consumers to their product but also place the products at affordable prices. The model posits that big time manufacturers usually carry out market research before tagging a price on their product to: know the income level of greater percentage of their consumers, find out the value that is lacking in the competing brand and know what the consumers are looking for in a product. When they find out, they include such needs in the product, state them in the product pack and still keep it at affordable price. These make the product to sell more than the competing brands.

\section{METHOD}

This study was designed as a survey. The geographical area of this study was Onitsha, Anambra State, Nigeria. The city has two local government areas: Onitsha North and Onitsha South. Onitsha has big motor parks and Mama put food vendors operate in these parks. The availability of mama put food outlets means the commercial bus drivers are likely to be patronising them. Theoretically, the population for this study comprises all the commercial bus drivers operating in motor parks in Onitsha. According to Onitsha Urban Drivers Association there are about 5,000 registered commercial bus drivers in Onitsha. A sample of 352 drivers was purposefully selected from the study, drawn from a study population of 5,000. This sample size had been determined for this study by looking at the different sample sizes worked out by Meyer (1973) for populations ranging from 1000 to infinity at 95 per cent confidence level.

The city of Onitsha was purposely selected because it is the commercial nerve centre of South East, Nigeria and also has the highest number of motor parks in the South East of the country. So there is the possibility of getting a good number of respondents with different perception about mama put food outlets. Upper Iweka motor park was purposely selected because it is the largest among all the parks in Onitsha. Also, it is the park where one can get buses going to all the thirty-six states of Nigeria including the Federal Capital Territory (FCT), Abuja. We distributed 357 copies of the questionnaire to respondents in Upper Iweka motor park. Data were collected in September 2018 through a cross-sectional quantitative survey with 357 commercial bus drivers who were all men. Participants were volunteers who were met accidentally at the Upper Iweka Motor Park, Onitsha. Two research assistants were recruited and trained for the purpose of data collection as already mentioned. Data collection took place within the span of two weeks. Each research assistant had a return rate of nearly 98 percent.

\section{RESULTS}

The data collected from our respondents, which was based on 352 respondents, revealed a wide range of conclusions. We have these presented in table with accompanying analysis and interpretation.

\subsection{Patronage of MAMA PUT Food Outlets}

In this section the primary goal was to determine if the respondents patronise mama put food outlets. And the questions on this issue were measured using question items 4-7 in the questionnaire. The data generated from the patronage of mama put food outlets variables are as presented below.

Table 5. Possibility of the Respondents Eating at Mama Put Food Outlets

\begin{tabular}{|lcc|}
\hline Options & Respondents & $\%$ \\
\hline Yes & 347 & $98.6 \%$ \\
No & 5 & $1.4 \%$ \\
Total & 352 & 100 \\
\hline
\end{tabular}

Table 5 shows that almost all the respondents eat at mama put food because out of the 352 respondents, 347 $(98.6 \%)$ agreed while only $5(1.4 \%)$ said no. 
Table 6. How often Respondents Eat at Mama Put Food Outlets

\begin{tabular}{|lcc|}
\hline Options & Respondents & $\%$ \\
\hline Regularly & 338 & 96.0 \\
Occasionally & 14 & 4.0 \\
Total & 352 & 100 \\
\hline
\end{tabular}

The data in Table 6 indicate that a little percentage (4.0) $(\mathrm{N}=14)$ said they eat at mama put food outlets occasionally while greater number of the respondents $(96.0 \%)(\mathrm{N}=338)$ said they eat regularly at mama put food outlets.

Table 7. The Issue that Prompts Respondents to Eat at Mama Put Food Outlets

\begin{tabular}{|lcl|}
\hline Options & Respondents & $\%$ \\
\hline Nearness to the motor park & 310 & 88.0 \\
Taste & 15 & 4.3 \\
Nourishment & 7 & 2.0 \\
All of the above & 20 & 5.7 \\
Total & 352 & 100 \\
\hline
\end{tabular}

Here the issue that prompts the commercial bus drivers in Onitsha to eat at mama put food outlets was presented. The data in Table 7 show that $88.0 \%(\mathrm{~N}=310)$ eat at mama put food outlets because of nearness to the park. Then All of the above recorded $5.7 \%(\mathrm{~N}=20)$, Taste has $4.3 \%(\mathrm{~N}=15)$ while $2.0 \%$ said they eat there because of nourishment

Table 8. Respondents Favourite Food at Mama Put Food Outlets

\begin{tabular}{|lcc|}
\hline Options & Respondents & $\%$ \\
\hline Rice and Stew & 44 & 12.5 \\
Beans and Yam & 24 & 6.8 \\
Foo-foo and Soup & 284 & 80.7 \\
Total & 352 & 100 \\
\hline
\end{tabular}

The analysis in Table 8 shows that all the respondents eat various types of food at mama put food outlets. The data show that $80.7 \%(\mathrm{~N}=284)$ of the respondents which was the highest number confessed that they prefer foofoo and soup to Rice and stew $(12.5 \%, \mathrm{~N}=44)$ and Beans and yam $(6.8 \%, \mathrm{~N}=24)$.

\subsection{Hygienic Knowledge of Mama Put Food Outlets}

Data on respondents' hygienic knowledge of mama were generated by using question items 8-9 in the questionnaire These data were presented using a percent distribution table.

Table 9. Respondents who are Health Information Literate

\begin{tabular}{|lcc|}
\hline Options & Respondents & $\%$ \\
\hline Yes & 28 & 8 \\
No & 324 & 92 \\
Total & 352 & 100 \\
\hline
\end{tabular}

In table 9, an attempt was made to establish if the respondents are health information literate. The data generated shows that almost all of them $(92 \%, N=324)$ are not health information literate. Only $8 \%(\mathrm{~N}=28)$ said yes.

Table 10. Respondents' Knowledge of Expose to Food Poison by Patronising Mama Put Food Outlets

\begin{tabular}{|lcc|}
\hline Options & Respondents & $\%$ \\
\hline Yes & 2 & 0.57 \\
No & 350 & 99.4 \\
Total & 352 & 100 \\
\hline
\end{tabular}


Here the frequency on whether the respondents are aware that patronising mama put food outlets exposes them to food poison. The data demonstrated that $99.4 \%(\mathrm{~N}=350)$ are not aware while $0.57 \%(\mathrm{~N}=2)$ said they are aware.

\subsection{Factors That Prompt Patronage}

An attempt was made to establish the factors that prompt respondents to patronise mama put food outlets. This was done by using variables $10-11$ in the questionnaire. The data generated are as presented below.

Table 11. Issue that Informs Patronage of Mama Put Food Outlets

\begin{tabular}{|lcc|}
\hline Options & Respondents & $\%$ \\
\hline Quality & 97 & 27.6 \\
Quantity & 255 & 72.4 \\
Total & 352 & 100 \\
\hline
\end{tabular}

In Table 11 above, $72.4 \%(\mathrm{~N}=255)$ of the respondents said that they patronise mama put food outlets because of quantity of the food while $27.6 \%(\mathrm{~N}=97)$ said it is because of quality.

Table 12. Factors that Influence Patronage of Mama Put Food Outlets

\begin{tabular}{|lcc|}
\hline Options & Respondents & $\%$ \\
\hline Appearance & 8 & 2.3 \\
Ingredients Used & 70 & 19.9 \\
Price & 274 & 77.8 \\
Total & 352 & 100 \\
\hline
\end{tabular}

Data in Table 12 show that $77.8 \%(\mathrm{~N}=274)$ of the respondents said that they patronise mama put food outlets because of the price; the respondents that went for Ingredients recorded $19.9(\mathrm{~N}=70)$; while Appearance has $2.3 \%(\mathrm{~N}=8)$.

\section{ANALYSIS OF RESEARCH QUESTION}

This study had four specific objectives: 1) to ascertain if commercial bus drivers have knowledge of health information; 2) to find out if they patronise mama put food outlet; 3) to determine whether commercial bus drivers believe that patronising mama put food outlet easily exposes them to food poison; 4) to ascertain if there are factors that influence them to patronise mama put food outlet. The four research questions posed in this study revolved around these objectives. Data interpretations were used to answer the research questions.

The first research question of this study sought to determine the number of commercial bus drivers that are health information literate. The analyses of the findings in Table 9 give an overall picture of respondents who have the knowledge of health information. This suggests that majority of the consumers $(92 \%, \mathrm{~N}=324)$ do not have the hygienic knowledge of mama put food outlets. Only $8 \%(\mathrm{~N}=28)$ said yes.

The second research question of this study sought to know the extent to which commercial bus drivers patronise mama put food outlets. The analysis of the respondents' eating at mama put food outlets in Tables 5 shows that almost all of them $(98.6 \%)$ eat at mama put food outlets. Also, the data in Table 6 reveal that a greater number of the respondents $(96.0 \%, \mathrm{~N}=338)$ said that they ate regularly at mama put food outlets.

The third research question sought to determine whether consumers believed that patronising mama put food outlet easily exposed them to food poison.

Data on Table 9 reveal that almost all the respondents $(92 \%, \mathrm{~N}=324)$ do not have hygienic knowledge of mama put food outlets while $8 \%(\mathrm{~N}=28)$ said they do. Also, information on Table 10 reveals that almost all of them $(99.4 \%, \mathrm{~N}=350)$ confessed that they do not have knowledge that patronising mama put food outlets exposes them to food poison. These findings support Adunwoke (2015) which reveals that many customers patronising mama put food outlets do not consider the hygienic condition of the environment where the food is prepared and sold. 
The fourth research question sought to ascertain if there are factors that influence commercial bus drivers to patronise mama put food outlets. The information in Table 11 suggests that most of the respondents $(72.4 \%$, $\mathrm{N}=255$ ) said that they patronise mama put food outlets because of price. Furthermore, data on Table 12 also state that Price $(77.8 \%)$ is the major factor that influences consumers to patronise mama put food outlets. This observation corresponds with European Food Information Council (EUFIC) (2012) which finds out that price of a product and monthly earning of the consumer are two major socio-economic factors that make a consumer to purchase a product.

\section{DISCUSSION OF FINDINGS}

The data analyzed in this study was obtained from 352 commercial bus drivers in the city of Onitsha. The overall results offer a wide range of conclusions. The key research question asked was to know how many commercial bus drivers have knowledge of health information. Findings in Table 9 led to the conclusion that commercial bus drivers in Onitsha $((92 \%, \mathrm{~N}=324))$ are not health information literate that is having knowledge of health or hygienic information about mama put food outlets. Only $8 \%(\mathrm{~N}=28)$ said yes. This supports the findings of Khairuzzaman (2014) that many consumers do not pay attention to health information concerning what they eat. On the extent to which commercial bus drivers patronise mama put food outlets, information on Table 6 reveal that $(96.0 \%, \mathrm{~N}=338)$ of the respondents said that they eat regularly at mama put food outlets. This supports Odeyemi (2015) which states that commercial bus drivers are one of the regular customers of mama put food outlets. The finding in Table 12 state that majority of the respondents $(77.8 \%)$ believe that price is the major factor that influences them to patronise mama put food outlets.

By and large, all these other findings constitute adjunct conclusions to the key conclusion which holds that the respondents studied are not health information literate; price is the major factor that influences commercial bus drivers to patronise mama put food outlets.

\section{CONCLUSION}

This study used survey questions to establish whether commercial bus drivers in Onitsha are health information literate concerning their patronage of mama put food outlets and their sense of vulnerability to food poison.

The study arrived at these conclusions: that majority of commercial bus drivers in Onitsha patronise mama put food outlets; commercial bus drivers in Onitsha are not health information literate; they do not believe that patronising mama put food outlets exposes them to food poison; quantity and price are the major factors that influence them to patronise mama put food outlets.

These conclusions were meant as a lead and not a generalization as there is necessity for replicative studies to be conducted in other African countries and other states in Nigeria to determine what the scenario is in such states.

\subsection{RECOMMENDATIONS}

The issue of health information literacy is an important subject matter in health communication. Many consumers are ignorant of the link between the environment where food is prepared/sold and their health. Against this backdrop, this study recommends that:

i. Health inspectors need to regularly train and monitor mama put food operators. They need not to be closed down because many drivers cannot afford to spend $¥ 500$ to eat a plate of food in fancy restaurant. Health regulatory bodies should educate both the mama put food vendors and the commercial bus drivers on the importance of hygienic environment where food is prepared or sold.

ii. There should be periodic check on mama put food vendors by the regulatory agencies to make sure they operate according to the regulation given to them when they were applying for license.

iii. There should be an honest effort on the part of mama put food vendours in making sure that they adhere to the hygienic conditions given to them by the health agency while licensing them for operation.

iv. Mama put food operators should embark on constant hand washing hygiene practice while on duty. This will serve as preventive measure to transmission of any disease. Food vendor operators should also go for medical examination for diseases like tuberculosis which can be transmitted through coughing. 


\section{REFERENCES}

Adunwoke, P. (2015). Visiting Roadside Mama put and Its Health Implication. The Guardian Newspaper, December 20, 2015.

Behnke, C.; Seo, S. and Miller, K. (2012). Assessing Food Safety Practices in Farmers' Market. Food Prot. Trens 32(5): 232-240.

Clark, K. (2013). Fighting Fake Food Information: How to Decipher Food Marketing Gimmicks and Become a Smart Shopper. Retrieved from www.katieclark.com on $21^{\text {st }}$ September, 2018.

Fill, C. (2006). Marketing Communication: Engagement, Strategy And Practice (Fourth Edition). New York: Prentice Hall

Grizzell, J. (2007). Behavior Change theories and Models. Retrieved from www.csupomona.edu on $17^{\text {th }}$ September, 2018.

Hasan, S. (2014) Mass Communication: Principles and Concept (Second edition). New Delhi:

CBS Publishers \& Distributors Pvt Ltd.

Khairuzzaman, M.; Chowdhury, F. M.; Emon, S. Z. and Bari, L. (2014). Food Safety Challenges towards Safe, Healthy, and Nutritious Street Foods in Bangladesh. In International Journal of Food Science. 1-9. DOI: $10.1155 / 2014 / 483519$.

Mclntyre, L.; Karden, L.; Shyng, S.; and Allen, K (2014). Survey of Observed Vendor Foodhandling Practices at Farmers' Markets in British Columbia, Canada. Retrieved from www.foodprotection.org on $22^{\text {nd }}$ September, 2018.

Magloff, L. (2015). "Push \& Pull Promotional Strategy" Hearst Newspapers, LLC. Retrieved from www.myhearstnewspaper.com/houston on $22^{\text {nd }}$ September, 2018.

Odeyemi, L. (2015). Food Business: Nigeria's Famous 'Mama Put' Remains Profitable. Bizwatch Newspaper, June 20, 2015. 